\title{
OR6-005 - Cystine crystals activate inflammasomes
}

\author{
G Prencipe $^{1^{*}}$, I Caiello ${ }^{1}$, S Petrini ${ }^{1}$, L Bracci Laudiero ${ }^{1}$, F Emma², F De Benedetti ${ }^{3}$ \\ From 7th Congress of International Society of Systemic Auto-Inflammatory Diseases (ISSAID) \\ Lausanne, Switerland. 22-26 May 2013
}

\section{Introduction}

Nephropathic cystinosis is a rare autosomal recessive disorder caused by a mutation in the CTNS gene, which encodes for cystinosin. It is characterized by the lysosomal accumulation of cystine, which leads to the formation of cystine crystals within various organs, including kidneys, brain, cornea, intestine and bone marrow. The exact role of intralysosomal cystine crystals accumulation in the pathogenesis of clinical features of cystinosis is still unclear, although it is well known that cystine levels are directly proportional to disease severity.

\section{Objectives}

In this study, we investigate whether cystine crystals are able to elicit inflammasome activation.

\section{Methods}

Primary human peripheral blood mononuclear cells (PBMCs) were cultured in vitro, pre-incubated with LPS, stimulated with L-cystine crystals in presence or absence of different inhibitors and the IL-1beta (IL-1b) released in the medium was measured by ELISA.

\section{Results}

LPS-primed PBMCs stimulated with L-cystine crystals secreted IL-1b in a dose-dependent manner. Similarly to other NLRP3-activating particles, cystine crystal-induced IL-1b secretion was caspase-1-dependent. Indeed, when PBMCs were pre-icubated with the specific CASP-1 inhibitor (Z-YVAD-fmk), a dramatic decrease in IL-1 $\beta$ production was observed, suggesting the involvement of an inflammasome-mediated pathway. By confocal microscopy, we observed that exogenous L-cystine crystals were internalized by monocytic/macrophagic adherent cells. Inhibition of actin polymerization with cytochalasin

'Laboratory of Rheumatology, Bambino Gesù Children's Hospital, Roma, Italy Full list of author information is available at the end of the article
D effectively blocked cystine crystal-induced IL-1 $\beta$ secretion, showing that phagocytosis is necessary for this effect.

\section{Conclusion}

Taken together, these data demonstrate that cystine crystals represent a new endogenous inflammasome activating danger signal, suggesting a new role for cystine crystals in the pathogenesis of nephropathic cystinosis.

\section{Disclosure of interest}

None declared.

\section{Authors' details}

'Laboratory of Rheumatology, Bambino Gesù Children's Hospital, Roma, Italy. ${ }^{2}$ Department of Nephrology and Urology, Bambino Gesù Children's Hospital, Roma, Italy. ${ }^{3}$ Operative Unit of Rheumatology, Bambino Gesù Children's Hospital, Roma, Italy.

Published: 8 November 2013

doi:10.1186/1546-0096-11-S1-A100

Cite this article as: Prencipe et al:: OR6-005 - Cystine crystals activate inflammasomes. Pediatric Rheumatology 2013 11(Suppl 1):A100.

Submit your next manuscript to BioMed Central and take full advantage of:

- Convenient online submission

- Thorough peer review

- No space constraints or color figure charges

- Immediate publication on acceptance

- Inclusion in PubMed, CAS, Scopus and Google Scholar

- Research which is freely available for redistribution

\section{Ciomed Central}

